\title{
Fluoride removal from brackish groundwater by direct contact membrane distillation
}

\author{
D. Y. Hou, J. Wang, B. Q. Wang, Z. K. Luan, X. C. Sun and X. J. Ren
}

\begin{abstract}
The direct contact membrane distillation (DCMD) applied for fluoride removal from brackish groundwater is presented. The self-prepared polyvinylidene fluoride membrane exhibited high rejection of inorganic salt solutes and a maximum permeate flux $35.6 \mathrm{kgm}^{-2} \mathrm{~h}^{-1}$ was obtained. The feed concentration had no marked impact on the permeate flux and the rejection of fluoride. The precipitation of $\mathrm{CaCO}_{3}$ would clog the hollow fiber inlets and foul the membrane surface with the increase of concentration factor when natural groundwater was used directly as the feed, which resulted in a rapid decline of the module efficiency. This phenomenon was diminished by acidification of the feed. The experimental results showed that the permeate flux and the quality of obtained distillate kept stable before concentration factor reached 5.0 with the acidified groundwater as feed. The membrane module efficiency began to decline gradually when the feed continued to be concentrated, which can be mainly attributed to the formation of $\mathrm{CaF}_{2}$ deposits on the membrane surface. Finally, a $300 \mathrm{~h}$ continuous fluoride removal experiment on acidified groundwater was carried out with concentration factor at 4.0, the permeate flux kept stable and the permeate fluoride was not detected.
\end{abstract}

Key words | brackish groundwater, fluoride removal, membrane distillation

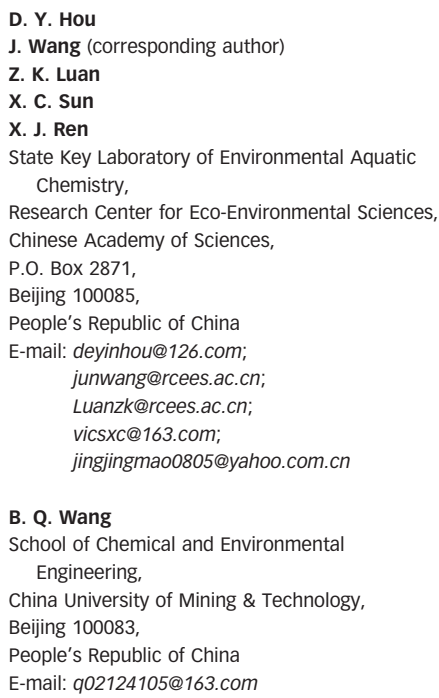

\section{INTRODUCTION}

In many parts of North and Northwest China, the groundwater is brackish and contains over $1.5 \mathrm{mg} \mathrm{L}^{-1}$ fluoride. It is well known that excessive fluoride in drinking water causes harmful effects such as dental and skeletal fluorosis (Amor et al. 200I). The World Health Organization has set a guidance value of $1.5 \mathrm{mg} \mathrm{L}^{-1}$ for fluoride in drinking water and the Chinese drinking water standard for it has been amended to $1.0 \mathrm{mg} \mathrm{L}^{-1}$. Because of the permanent risks, fluoride removal from water with high fluoride content becomes necessary.

Nowadays, the methods developed for fluoride removal from drinking water are mainly adsorption (Yang \& Dluhy 2002), precipitation (Mameri et al. 1998), ion exchange (Dieye et al. I998; Castel et al. 2000), and membrane processes (Tahaikt et al. 2004; $\mathrm{Hu} \&$ Dickson 2006). To effectively decrease fluoride by precipitation requires a doi: $10.2166 /$ wst.2010.878 large amount of chemicals. This process also creates a certain volume of sludge, which needs further treatments before disposing it into the environment. Ion-exchange process can remove fluoride up to $90-95 \%$, but this process will release noxious chemical reagents used in the resin regeneration into the environment ( $\mathrm{Qu}$ et al. 2009) and the treated water has a very low $\mathrm{pH}$ and high levels of chloride (Meenakshi \& Maheshwari 2006). Adsorption was considered as the most efficient and applicable technology for fluoride removal from drinking water ( $\mathrm{Wu}$ et al. 2007). Activated alumina (Ghorai \& Pant 2004), activated carbon (Muthukumaran et al. I995), bone charcoal (Bhargava \& Killedar I992), oxides (Raichur \& Basu 200I) and other lowcost materials (Çengeloğlu et al. 2002; Agarwal et al. 2003) have been used as fluoride adsorbents. Adsorption process can remove fluoride up to $90 \%$ and the treatment is 
cost-effective. However, this method requires a regeneration process after the adsorbents being exhausted, which may decrease the absorption capacity of adsorbents.

Reverse osmosis (RO) and nanofiltration (NF) are two common pressure driven membrane processes used for fluoride removal. RO is actually efficient since it sharply reduced the content of inorganic matters in water. But the RO membranes are particularly susceptible to scaling and fouling, so it is very difficult to maintain the constant permeate flux (Afonso et al. 2004). In addition, a high pressure is necessary in RO membrane system, which results in the increase of the desalination cost (Hasson et al. 200I). In NF process, although less pressure is needed, NF can just ensure the reduction of bivalent ions and it is insufficient to obtain drinking water from brackish water which contains lots of monovalent ions, the total dissolved solid (TDS) of the permeate obtained with this process is superior to the standard value (Walha et al. 2007). Electrodialysis (ED) is an electrical-driven membrane technology, which is effective with fluoride removal from feed and not sensitive to $\mathrm{pH}$ or hardness levels. However, when using ED technology for desalination, treatment cost is directly related to the TDS concentration in feed. This technology is best used in treating brackish water with TDS up to $4,000 \mathrm{mg} \mathrm{L}^{-1}$ and not economical for higher TDS concentration (Younos \& Tulou 2005).

Membrane distillation (MD) is a kind of thermally driven membrane separation process and usually applied in which water is the major component present in the feed solution to be treated. The permeate flux of MD is driven by a vapor pressure difference across the porous hydrophobic membrane resulting from the temperature difference and solution composition gradients in the boundary layers adjacent the membrane. During the MD process of solutions with non-volatile solutes, only water vapor can transfer through the membrane. Thus, in theory, the MD process enables the production of pure water from natural water. In comparison with the pressure-driven membrane processes, MD is less dependent on the initial salinity of the feed as well as a higher salt rejection ratio. In recent years, MD has been applied for water desalination, juice concentration processing and other industrial areas (Gryta \& Karakulski 1999; Zakrzewska et al. 200I).
Direct contact membrane distillation (DCMD) is the best known configuration of MD, in which the feed and the distillate are directly separated by the hydrophobic membrane. DCMD is considered to be the most simple in design and appears as the best for application because condensation is carried out inside the membrane module. The main objective of this work was to study the feasibility of the removal of fluoride from brackish groundwater by DCMD process with self-prepared PVDF membrane. The process was examined under different values of feed temperature, flow rate and feed fluoride concentration. Finally, the DCMD process was applied to the fluoride removal from natural brackish groundwater. The effect of pre-acidification on the process performance in terms of flux stability and rejection was also investigated.

\section{MATERIALS AND METHODS}

\section{Reagents and analysis methods}

All chemicals used in the experiments were of analytical reagent grade. $\mathrm{NaF}$ was obtained from Beijing Chemical works (China). Fluoride solution was prepared by dissolving $\mathrm{NaF}$ with deionized water, and other solutions were also prepared with deionized water.

Analysis of $\mathrm{F}^{-}, \mathrm{Cl}^{-}, \mathrm{SO}_{4}^{2-}$ and $\mathrm{PO}_{4}^{3-}$ were made by ion chromatograph (861, Metrohm, Switzerland). Total phosphorus (TP) and dissolved silica were determined by the Ammonium molybdate spectrophotometric method and the Hetropoly blue method, respectively. Total organic carbon (TOC) was determined by TOC analyzer (8000, Phoenix, USA). $\mathrm{K}^{+}, \mathrm{Na}^{+}, \mathrm{Ca}^{2+}$ and $\mathrm{Mg}^{2+}$ were analyzed on ICP-AES (1200, Agilent, USA). Alkalinity, carbonate and bicarbonate were measured using an alkalinity titration. The conductivity of the feed was measured using a conductivity meter (CO150, HACH, USA).

\section{Membrane and membrane module}

The hydrophobic polyvinylidene fluoride (PVDF) hollow fiber membranes used in the experiments were selfprepared by dry/wet phase inversion process and the membrane characteristics are shown in Table 1. 
Table 1 | Measured data of membrane characteristics

\begin{tabular}{ll} 
Parameter & Value \\
\hline Mean pore diameter $(\mu \mathrm{m})$ & 0.25 \\
OD/ID* $(\mathrm{mm} / \mathrm{mm})$ & $1.20 / 0.90$ \\
Wall thickness $(\mathrm{mm})$ & 0.15 \\
Porosity $(\%)$ & 75.30 \\
$\mathrm{LEPw}^{\dagger}(\mathrm{kPa})$ & 150 \\
\hline
\end{tabular}

*Outer diameter/Inner diameter.

${ }^{\dagger}$ Liquid entry pressure of water

The dry PVDF hollow fibers were assembled into a polyester tube (diameter $(\mathrm{mm}) d_{\text {in }} / d_{\text {out }}=15 / 20$ ) with two UPVC T-tubes and two ends of the bundle of fibers were sealed with solidified epoxy resin to form a membrane module. The module had a total length of $240 \mathrm{~mm}$ and an effective length of $100 \mathrm{~mm}$. The packing fraction of hollow fibers in the module was about 32\%. The total effective area of the module was about $0.014 \mathrm{~m}^{2}$ based on the inner surface.

\section{Experimental setup}

The schematic representation of DCMD setup is shown in Figure 1. The hot salt solution as the feed liquid flowed co-currently through the lumen side of the fibers and the cold distillate flowed through the shell side using two rotameters (LZS-15, Yuyao Yinhuan Flowmeter, China) to adjust the flow rate. Both solutions were circulated in the membrane module with the help of two magnetic pumps (MP-15RN, Shanghai Seisun Bumps, China).

The feed temperature was controlled by a Pt-100 sensor and a heater connected to an external thermostat (XMTD2202, Yongshang Instruments, China) and the temperature of cold distillate water was controlled by pumping through a spiral glass heat exchanger located in the constant temperature trough of the cooler (SDC-6, Nanjing Xinchen Biotechnology, China). The temperature of both fluids was monitored at the inlet and outlet of the membrane module using four thermometers with an accuracy of $\pm 0.1^{\circ} \mathrm{C}$. The conductivity of the cold distillate was investigated with an electric conductivity monitor (CM-230A, Shijiazhuang Create Instrumentation Technologies, China).

\section{Solute rejection test}

To investigate whether the hydrophobic PVDF hollow fiber membranes could be applicable for desalination, the DCMD experiments of $0.10 \mathrm{M} \mathrm{NaCl}, \mathrm{MgSO}_{4}$ and $\mathrm{CaCl}_{2}$ aqueous solutions were conducted at $\mathrm{pH} 4.0$ and 9.0 with the feed solution at $50^{\circ} \mathrm{C}$ and the cold distillate water at $20^{\circ} \mathrm{C}$. The $\mathrm{pH}$ of the feed was adjusted by addition of $0.1 \mathrm{M}$ $\mathrm{HCl}$ or $0.1 \mathrm{M} \mathrm{NaOH}$. The feed and distillate flow rates were kept at 0.52 and $0.15 \mathrm{~m} \mathrm{~s}^{-1}$, respectively. The solute rejection coefficient $R$ of the membrane was calculated

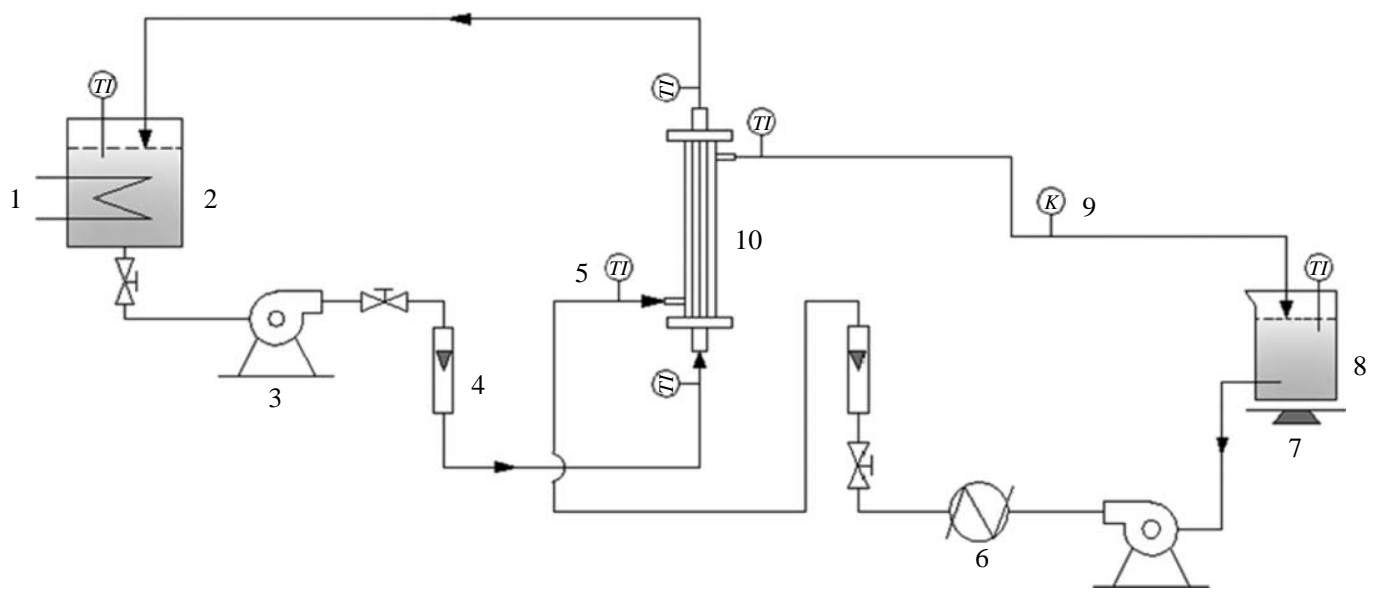

Figure 1 Schematic diagram of the experimental DCMD setup. (1) Heater, (2) Feed tank, (3) Circulating pump, (4) Flow meter, (5) Thermometer, (6) Water cooler, (7) Balance, (8) Distillate reservoir, (9) Conductivity meter, (10) Membrane module. 
according to the following equation:

$R=\frac{C_{\mathrm{f}}-C_{\mathrm{p}}}{C_{\mathrm{f}}}$

where $C_{\mathrm{f}}$ is the concentration of the feed and $C_{\mathrm{p}}$ is the concentration of the permeate.

\section{Fluoride removal experiments}

The sodium fluoride solutions were prepared in deionized water by diluting the prepared stock solutions $\left(5,000 \mathrm{mg} \mathrm{L}^{-1}\right)$ to desired concentrations. In specific experiments, composition of the feed water and operating parameters were chosen as below:

(i) Feed water was a $5 \mathrm{mg} \mathrm{L}^{-1}$ of fluoride solution at temperature ranging from 30 to $80^{\circ} \mathrm{C}$ and cold distillate water temperature at $20^{\circ} \mathrm{C}$. At each feed temperature, the feed flow rate $\left(V_{\mathrm{f}}\right)$ varied from 0.17 to $0.52 \mathrm{~m} \mathrm{~s}^{-1}$ and the distillate flow rate $\left(V_{\mathrm{p}}\right)$ was kept at constant $0.15 \mathrm{~m} \mathrm{~s}^{-1}$.

(ii) Feed water was a fluoride solution with different concentration $(5,10,50,100,500,1,000$ and $5,000 \mathrm{mg} \mathrm{L}^{-1}$ ) at $50^{\circ} \mathrm{C}$ and cold distillate water at $20^{\circ} \mathrm{C}$. The feed and distillate flow rates were kept at 0.52 and $0.15 \mathrm{~m} \mathrm{~s}^{-1}$, respectively.

\section{Natural groundwater application}

The natural groundwater was taken from the eastern region of Huining (Gansu Province, China). Table 2 gives the chemical composition of the untreated water sample, which is brackish and contains many excessive ions, especially fluoride.

Fluoride removal experiments of natural brackish groundwater by DCMD without or with $0.1 \mathrm{M} \mathrm{HCl}$ addition were carried out. During the fluoride removal process, the initial volume of feed was $5.0 \mathrm{~L}$ and there was no make-up water added into the feed tank, which meant that the feed solution was gradually concentrated. This concentration process was not stopped until the concentration factor reached 10.0 to get high water recovery. The inlet temperatures of feed and cold distillate kept constant at $50^{\circ} \mathrm{C}$ and $20^{\circ} \mathrm{C}$, respectively. The feed flow rate was $0.52 \mathrm{~m} \mathrm{~s}^{-1}$, while the permeate side being $0.15 \mathrm{~m} \mathrm{~s}^{-1}$.

\section{SEM analysis}

Both the fresh and the used membrane samples were dried in air at room temperature. Then the membrane samples were sputtered with gold and examined with a Hithche S-3000 scanning electron microscope (SEM) (Hitachi Ltd., Japan) to obtain high magnification membrane surface images. Elemental analysis of the scaled membranes was accomplished using energy dispersive X-ray spectroscopy (EDS) analysis system.

\section{RESULTS AND DISCUSSIONS}

\section{Solute rejection tests}

The solute rejection test results are listed in Table 3. During the desalination processes of the prepared $\mathrm{NaCl}, \mathrm{MgSO}_{4}$

\begin{tabular}{|c|c|c|c|}
\hline Constituent & Content & Constituent & content \\
\hline Temperature $\left({ }^{\circ} \mathrm{C}\right)$ & 20 & $\mathrm{TP}\left(\mathrm{mg} \mathrm{L}^{-1}\right)$ & 0.12 \\
\hline Turbidity (NTU) & 1.12 & $\mathrm{TOC}\left(\mathrm{mg} \mathrm{L}^{-1}\right)$ & 2.24 \\
\hline Conductivity $\left(\mathrm{mS} \mathrm{cm}^{-1}\right)$ & 6.90 & $\mathrm{~K}^{+}\left(\mathrm{mg} \mathrm{L}^{-1}\right)$ & 65 \\
\hline $\mathrm{pH}$ & 7.75 & $\mathrm{Ca}^{2+}\left(\mathrm{mg} \mathrm{L}^{-1}\right)$ & 200 \\
\hline $\mathrm{F}^{-}\left(\mathrm{mg} \mathrm{L}^{-1}\right)$ & 5 & $\mathrm{Na}^{+}\left(\mathrm{mg} \mathrm{L}^{-1}\right)$ & 1,160 \\
\hline $\mathrm{Cl}^{-}\left(\mathrm{mg} \mathrm{L}^{-1}\right)$ & 2,120 & $\mathrm{Mg}^{2+}\left(\mathrm{mgL}^{-1}\right)$ & 127 \\
\hline $\mathrm{SO}_{4}^{2-}\left(\mathrm{mg} \mathrm{L}^{-1}\right)$ & 510 & $\mathrm{SiO}_{2}$ (dissolved, $\mathrm{mg} \mathrm{L}^{-1}$ ) & 7.67 \\
\hline $\mathrm{HCO}_{3}^{-}\left(\mathrm{mg} \mathrm{L}^{-1}\right)$ & 135 & Hardness $\left(\mathrm{meq} \mathrm{L}^{-1}\right)$ & 21 \\
\hline $\mathrm{PO}_{4}^{3-}\left(\mathrm{mg} \mathrm{L}^{-1}\right)$ & Not detected & $\operatorname{TDS}\left(\mathrm{mg} \mathrm{L}^{-1}\right)$ & 4,322 \\
\hline
\end{tabular}


Table 3 | Rejection of non-volatile solutes by DCMD

\begin{tabular}{lllll} 
pH & $\begin{array}{l}\text { Solute } \\
(\mathbf{0 . 1} \mathbf{~ M )}\end{array}$ & $\begin{array}{l}\text { Feed conductivity } \\
\left(\mathbf{m s ~ c m}^{-\mathbf{1}}\right)\end{array}$ & $\begin{array}{l}\text { Permeate conductivity } \\
\left(\boldsymbol{\mu} \mathbf{S ~ c m}^{-\mathbf{1}}\right)\end{array}$ & $\begin{array}{l}\text { Rejection } \\
(\%)\end{array}$ \\
\hline 4.0 & $\mathrm{NaCl}$ & 10.27 & 2 & 99.99 \\
& $\mathrm{MgSO}_{4}$ & 5.62 & 3 & 99.99 \\
& $\mathrm{CaCl}_{2}$ & 14.64 & 2 & 99.99 \\
9.0 & $\mathrm{NaCl}^{*}$ & 10.45 & 2 & 99.99 \\
& $\mathrm{MgSO}_{4}$ & 5.55 & 2 & 99.99 \\
& $\mathrm{CaCl}_{2}$ & 14.42 & 3 & 99.99 \\
\hline
\end{tabular}

and $\mathrm{CaCl}_{2}$ aqueous solutions, all the solute rejection efficiencies can reach to $99.99 \%$ at $\mathrm{pH} 4.0$ and 9.0, which indicated that the membrane had no selective rejection of different non-volatile solutes and the $\mathrm{pH}$ had no significant influence on the solute rejection in weak alkaline and acidic mediums during the DCMD process. All the test results showed that the self-prepared PVDF membrane was suitable for DCMD application in fluoride removal from brackish water.

\section{Effect of feed temperature and flow rate}

The permeate flux as a function of feed temperature is shown in Figure 2. The experimental results showed that the feed temperature had a remarkable influence on the permeate flux. For example, the permeate flux increased from 2.9 to $35.6 \mathrm{kgm}^{-2} \mathrm{~h}^{-1}$ when the feed temperature changed from 30 to $80^{\circ} \mathrm{C}$ with the feed flow rate at

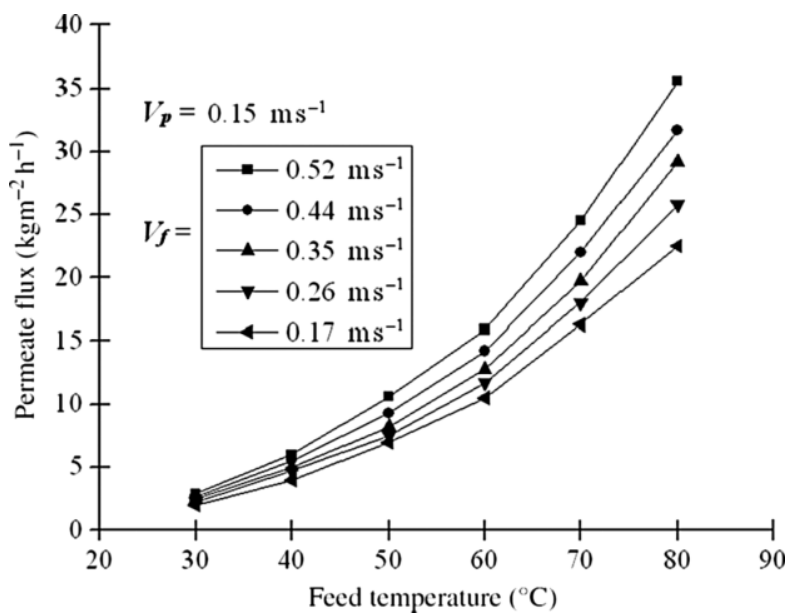

Figure 2 Variation of permeate flux as a function of the feed temperature and flow rate.
$0.52 \mathrm{~m} \mathrm{~s}^{-1}$. For all the feed flow rates, increasing the feed temperature enhanced the permeate flux. This trend may be explained by the Antoine equation which predicts an exponential relationship between the driving force (vapor pressure difference) and temperature. Besides, the viscosity of the feed declined with the increase of temperature, which was favorable to enhance mass transfer coefficient.

From Figure 2, it can also be found that the permeate flux increased with the increase of feed flow rate for all the feed temperatures. This was because of the temperature and concentration polarization phenomenon. The increase in heat transfer coefficient in boundary layer induced by the high feed flow rate resulted in the decrease of temperature difference between bulk streams and membrane surfaces. The concentration difference also declined for the same reason. Therefore, the permeate flux increased with the increase of feed flow rate.

\section{Effect of feed fluoride concentration}

The effect of feed concentration on the permeate flux is presented in Figure 3. It can be found that the influence of feed fluoride concentration on the permeate flux was not as significant as that of feed temperature or feed flow rate and the permeate flux was hardly affected by feed concentration in the studied range. When the feed fluoride concentration varied from 5 to $5,000 \mathrm{mg} \mathrm{L}^{-1}$, the permeate flux kept stable at about $10.5 \mathrm{kgm}^{-2} \mathrm{~h}^{-1}$. This finding is in agreement with the result previously reported by Alklaibi \& Lior (2006). According to Raoult's law, the saturated vapor partial

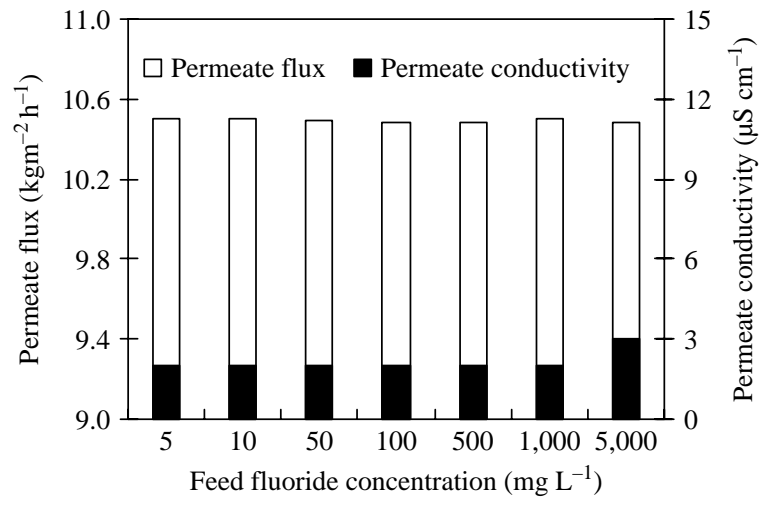

Figure 3 | Variation of permeate flux and permeate conductivity with different fluoride concentration. 


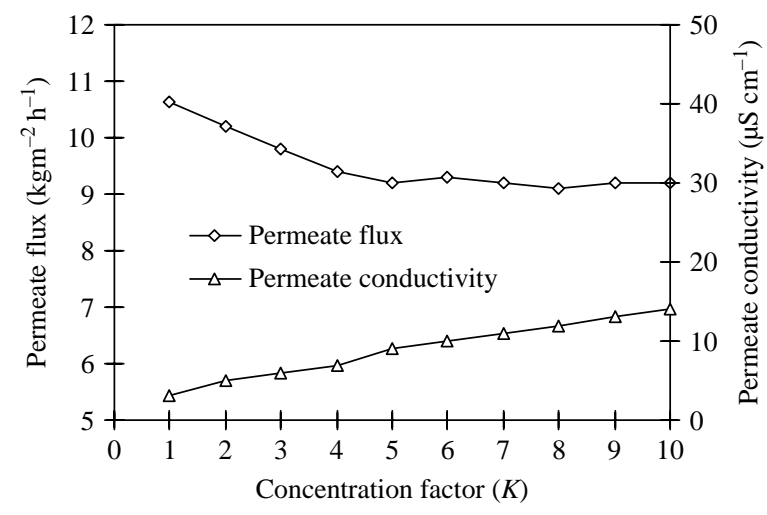

Figure 4 | Variation of permeate flux and permeate conductivity as a function of the feed concentration factor.

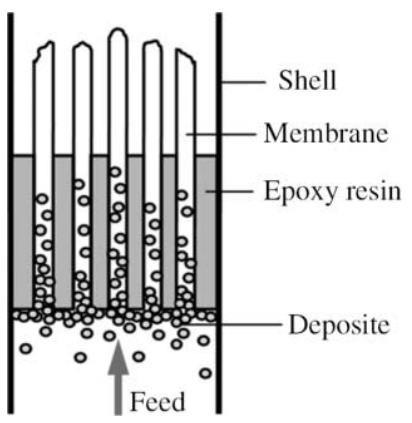

Figure $\mathbf{5}$ | Schematic presentation of the deposit accumulation at the hollow fiber inlets during the DCMD process.

pressure difference $(\Delta P)$ between pure water and dilute salt solution at same temperature can be calculated as follows:

$\Delta P=P_{0} \frac{m}{55.5}$

where $P_{0}$ is the saturated vapor pressure of pure water (Pa), $m$ is the molar concentration of solute in dilute salt solution $\left(\mathrm{mol} \mathrm{L}^{-1}\right)$. From Equation (2), it can be seen that the feed fluoride concentration has no significant effect on the saturated vapor partial pressure in the given fluoride concentration range of 5 to $5,000 \mathrm{mg} \mathrm{L}^{-1}$, so the permeate flux had no marked change with the increase of feed concentration.

In the fluoride concentration range of 5 to $1,000 \mathrm{mg} \mathrm{L}^{-1}$, feed fluoride concentration had no remarkable impact on the rejection, the permeate conductivity kept stable at $2 \mu \mathrm{S} \mathrm{cm}^{-1}$, which meant almost $100 \%$ rejection of fluoride. When feed fluoride concentration increased to $5,000 \mathrm{mg} \mathrm{L}^{-1}$, the permeate conductivity increased to $3 \mu \mathrm{S} \mathrm{cm}^{-1}$, this can be attributed to partial wetting phenomenon because of a small amount large pores existed on the membrane surface. Fortunately, the permeate fluorides were all below the detection limit during the whole process.

\section{DCMD process of natural groundwater}

The result of gradual concentration of natural groundwater is presented in Figure 4. As can be seen, the concentration factor $(K)$ had a marked influence on the DCMD performance. With the increase of the concentration factor, the permeate conductivity increased in line. The permeate flux decreased sharply before concentration factor reached 5.0 , then the permeate flux was fixed on a practically constant level of $9.2 \mathrm{kgm}^{-2} \mathrm{~h}^{-1}$.

All of these results were mainly due to the formation of deposit in the concentration process of brackish groundwater. Heating the feed caused a shift from bicarbonate ion to the carbonate ion and scale deposits were formed from
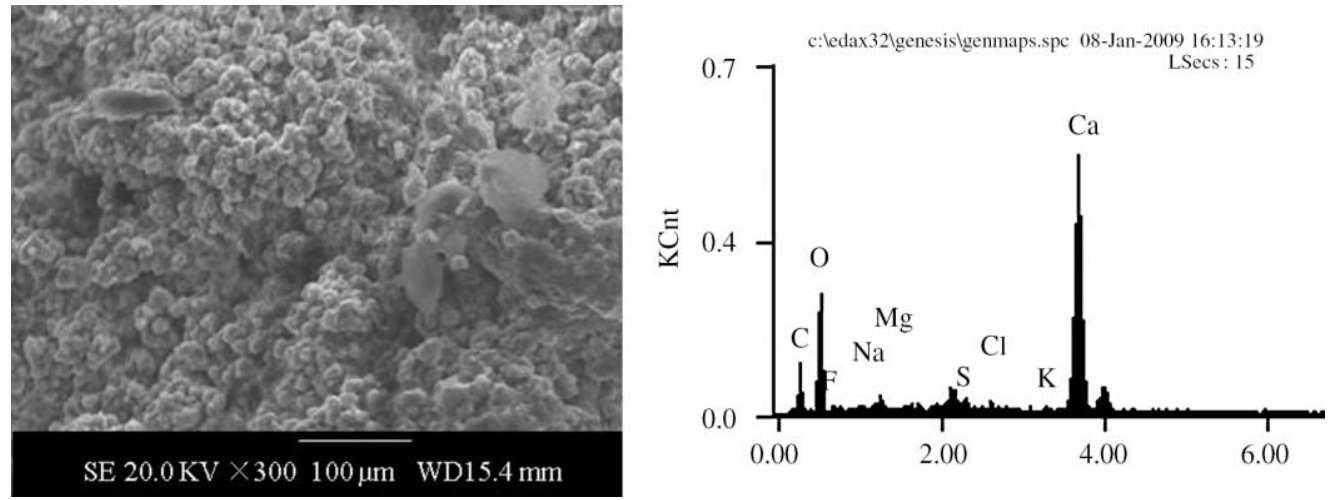

Figure 6 | SEM image and microanalysis report of the deposit formed at the hollow fiber inlets during the DCMD process. 


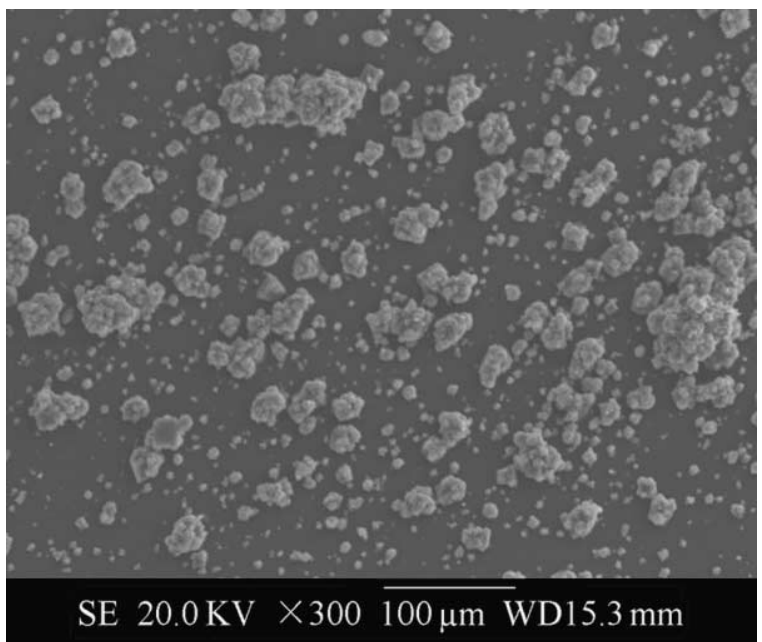

Figure 7 | SEM image of the deposit formed on the membrane surface during the DCMD process.

those salts whose solubility is generally limited because of their concentrations increase with the increase of concentration factor. The accumulation of scale deposits at the hollow fiber inlets caused the clogging of some hollow fibers and the decline of the feed flow rate, as a consequence, the permeate flux decreased. This situation is schematically shown in Figure 5. The SEM image of the deposits formed at the hollow fiber inlets is presented in Figure 6. The SEM-EDS analysis revealed that this deposit was mainly composed of $\mathrm{CaCO}_{3}$, with smaller amounts of the following elements: $\mathrm{Na}, \mathrm{Mg}, \mathrm{F}, \mathrm{Cl}$ and $\mathrm{S}$. Furthermore, the decline of the permeate flux shown in Figure 4 was also associated with the pore clogging by scale deposits formed on the

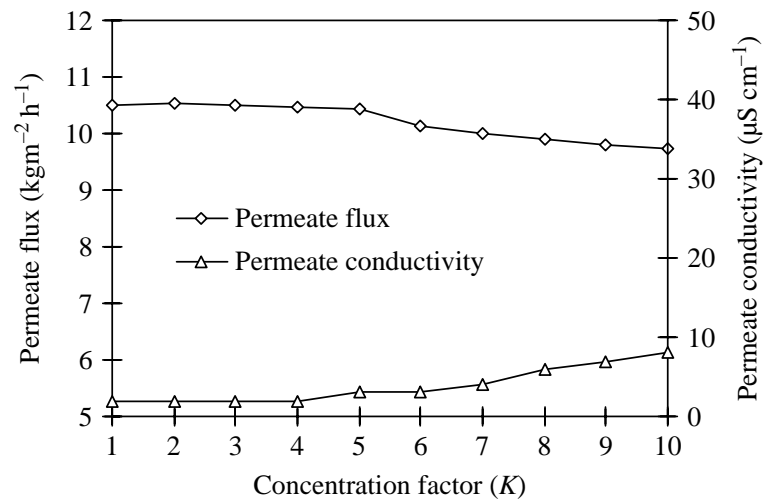

Figure 8 | Variation of permeate flux and permeate conductivity as a function of the feed concentration factor.

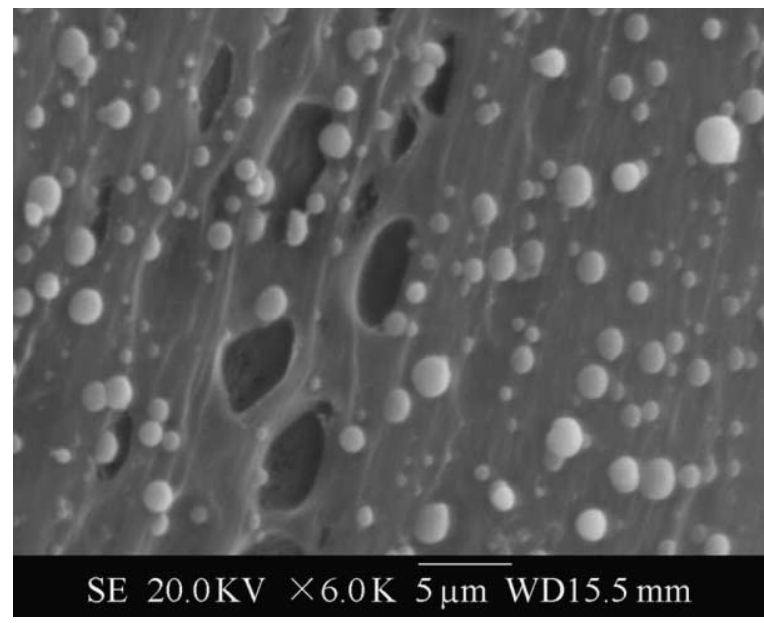

Figure 9 SEM image of the deposit formed on the membrane surface during the DCMD process.

membrane surface and the temperature and concentration polarization phenomenon caused by the increase of concentration factor.

The SEM image of the deposits formed on the membrane surface is shown in Figure 7. The scale deposits formed on the membrane surface caused the membrane wetting, and as a result, the permeate conductivity increased. In spite of wettability of a fraction of the membrane pores, the permeate conductivity kept below $15 \mu \mathrm{S} \mathrm{cm}^{-1}$ and the highest fluoride concentration of obtained distillate was $0.18 \mathrm{mg} \mathrm{L}^{-1}$, which was under the standards.

\section{DCMD of natural groundwater with pre-acidification}

In order to achieve the decomposition of the bicarbonate ions in the groundwater and eliminate the negative influence of scale deposits formation on the DCMD process, further studies of the DCMD process were carried out at the feed $\mathrm{pH}$ 4.0 adjusted by addition of $0.1 \mathrm{~mol} \mathrm{~L}^{-1} \mathrm{HCl}$ to the feed.

The result of gradual concentration of pre-acidified groundwater is presented in Figure 8. As can be seen, the acidification of the feed enhanced the stability of the process in a significant degree. There was no obvious decline of permeate flux before concentration factor reached 5.0, and the permeate conductivity stabilized at about $2.0 \mu \mathrm{S} \mathrm{cm}^{-1}$. All of these indicated that during this stage there was no scale deposit formed and the quality of the hydrophobic 


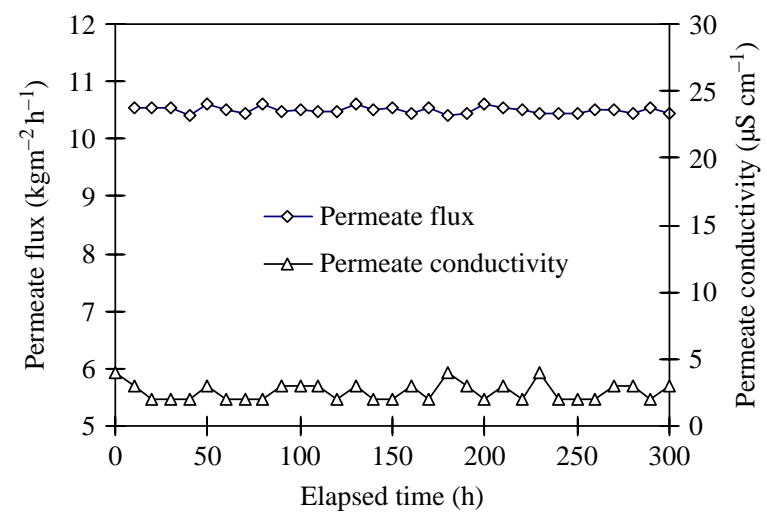

Figure $10 \mid$ Variation of permeate flux and permeate conductivity as a function of elapsed time.

membrane was maintained well. After concentration factor reached 5.0, the permeate flux began to decrease. When concentration factor increased from 5.0 to 10.0 , the permeate flux declined from 10.45 to $9.75 \mathrm{kgm}^{-2} \mathrm{~h}^{-1}$ and the permeate conductivity increased from 3.0 to $8.0 \mu \mathrm{S} \mathrm{cm}^{-1}$. This phenomenon can also be attributed to the formation of deposits, which formed on the membrane surface, clogged and wetted a fraction of the membrane pores.

From Figure 9, it can be obviously observed that the shape of the deposits is different from those shown in Figure 7 and the amount of the deposits is also smaller. The SEM-EDS analysis revealed that this deposit was mainly composed of $\mathrm{CaF}_{2}$, with smaller amounts of the following elements: $\mathrm{Na}, \mathrm{Mg}, \mathrm{Cl}$ and $\mathrm{S}$. Being different from the concentration process of natural groundwater without acidification, there was no deposit been found at the hollow fiber inlets and the feed flow rate kept stable during this experiment process. During this process, the fluoride concentration of obtained distillate kept below $0.10 \mathrm{mg} \mathrm{L}^{-1}$, which was also under the standards.

\section{Performance stability of DCMD}

To get high-quality potable water, it is important to maintain the permeability and solute rejection during the practical application. To investigate the retaining
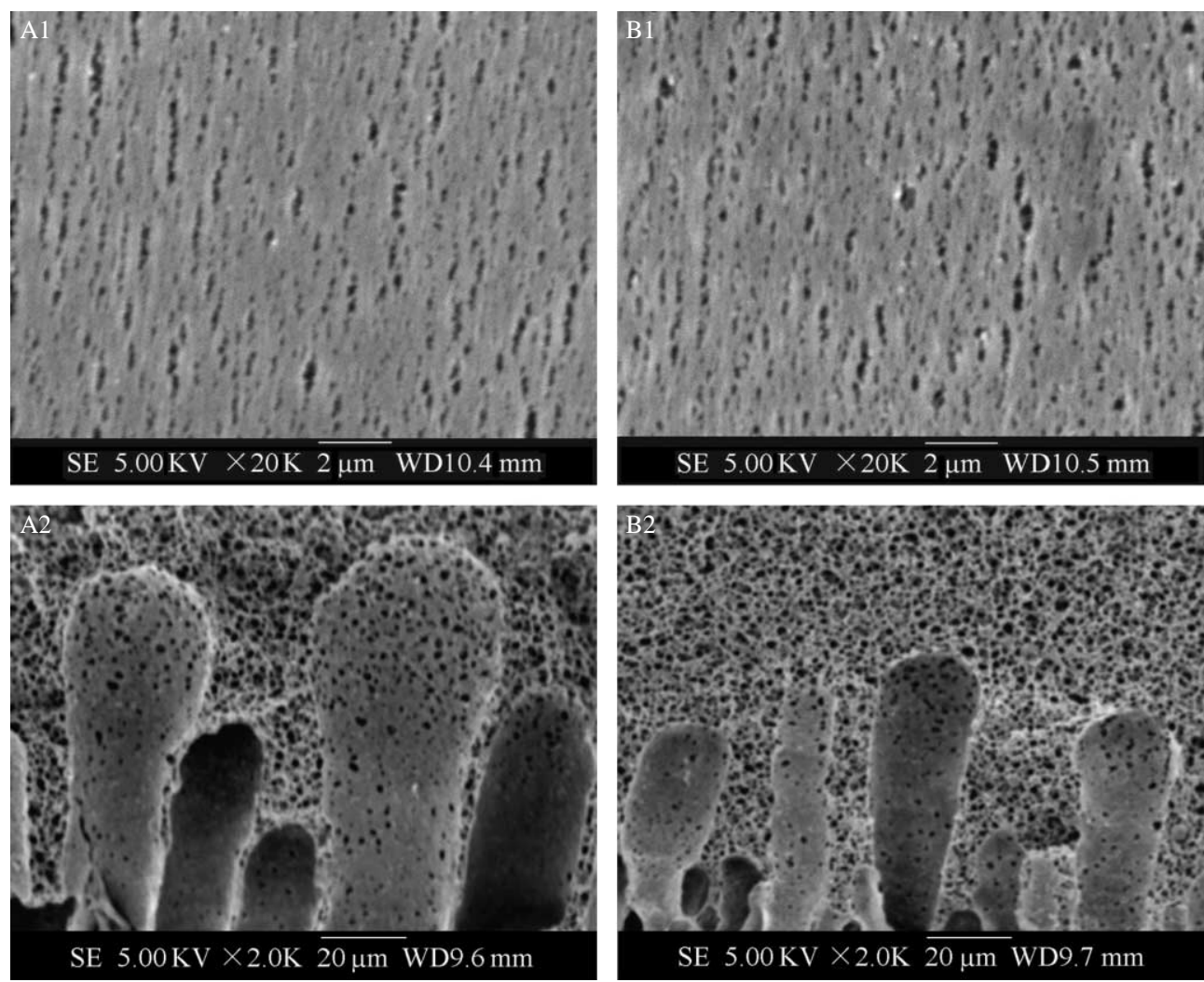

Figure 11 SEM micrographs of the PVDF membranes: (A1) inner surface of the fresh membrane, (A2) middle structure of the fresh membrane, (B1) inner surface of the membrane after $300 \mathrm{~h}$ fluoride removal experiment, (B2) middle structure of the membrane after $300 \mathrm{~h}$ fluoride removal experiment. 
performance stability of DCMD process, a $300 \mathrm{~h}$ continuous fluoride removal experiment of acidified groundwater with the $\mathrm{pH}$ at constant 4.0 was conducted with the feed solution at $50^{\circ} \mathrm{C}$ and the cold distillate water at $20.0^{\circ} \mathrm{C}$. During this process, the concentration factor was kept at 4.0, which meant that the water recovery reached about $75 \%$. The other operating parameters were in accordance with the solute rejection tests.

The experimental result is presented in Figure 10. It can be seen that the permeate flux maintains about $11.40-11.60 \mathrm{kgm}^{-2} \mathrm{~h}^{-1}$ during experiment and there are no obvious changes of permeate flux. The permeate conductivity stabilized at about $2.0-4.0 \mu \mathrm{Scm}^{-1}$ and the permeate fluoride were all below the detection limit. The SEM images of the hydrophobic PVDF membrane used in this process are presented in Figure 11. It can be found that there were no deposits formed on the inner surface of the membrane and there were also no marked changes of the membrane morphology. All of these demonstrated that the hydrophobic membrane had a stable permeability and solute rejection, the DCMD process was suitable for fluoride removal from brackish groundwater.

\section{CONCLUSIONS}

In the present work, the application of DCMD for fluoride removal from brackish groundwater was investigated systematically.

The self-prepared PVDF membrane had high rejection of non-volatile inorganic salt solutes, which were independent of the solution $\mathrm{pH}$. It was found that the permeate flux got enhanced with the increase of the feed temperature or flow rate, but the feed concentration had no marked impact on the permeate flux and the rejection of fluoride in the investigated concentration range. Furthermore, DCMD exhibited an excellent fluoride removal ability of highconcentration solutions. The experimental results showed that the permeate fluoride was below the detection limit even the feed fluoride increased to $5,000 \mathrm{mg} \mathrm{L}^{-1}$.

The application of DCMD for fluoride removal from brackish groundwater required acidification pretreatment, in particular, the removal of bicarbonate ions. Heating of the feed caused decomposition of bicarbonate ions present in feed and formed $\mathrm{CaCO}_{3}$ deposit with increase of the concentration factor. The deposit would clog the hollow fiber inlets and foul the membrane surface, which resulted in a rapid decline of the module efficiency. This phenomenon could be diminished by acidification of the feed. The experimental results showed that the permeate flux and the quality of obtained distillate kept stable before concentration factor reached 5.0 with the acidified groundwater as feed. The membrane module efficiency began to decline gradually when the feed continued to be concentrated, which can be mainly attributed to the formation of $\mathrm{CaF}_{2}$ deposits on the membrane surface.

The results of a $300 \mathrm{~h}$ continuous fluoride removal experiment of acidified groundwater with the $\mathrm{pH}$ at 4.0 and concentration factor at constant 4.0 showed that the permeate flux and the quality of the distillate obtained kept stable. During this process, there was no deposit formed on the membrane surface and the permeate fluoride was not detected. All of these demonstrated that DCMD could be efficiently used for removal of fluoride from brackish groundwater with water recovery at $75 \%$.

\section{ACKNOWLEDGEMENTS}

Financial support provided by the National Science and Technology Support Program of China (Grant no. 2006BADO1B02-02) and the special fund from the State Key Laboratory of Environmental Aquatic Chemistry (Project \# 08Y09ESPCR) are gratefully acknowledged.

\section{REFERENCES}

Afonso, M. D., Jaber, J. O. \& Mohsen, M. S. 2004 Brackish groundwater treatment by reverse osmosis in Jordan. Desalination 164(2), 157-171.

Agarwal, M., Rai, K., Shrivastav, R. \& Dass, S. 2003 Deflouridation of water using amended clay. J. Clean. Prod. 11(4), 439-444.

Alklaibi, A. M. \& Lior, N. 2006 Heat and mass transfer resistance analysis of membrane distillation. J. Membr. Sci. 282(1-2), $362-369$.

Amor, Z., Bariou, B., Mameri, N., Taky, M., Nicolas, S. \& Elmidaoui, A. 200I Fluoride removal from brackish water by electrodialysis. Desalination 133(1-3), 215-223. 
Bhargava, D. S. \& Killedar, D. J. 1992 Fluoride adsorption on fishbone charcoal though a moving media adsorber. Water Res. 26(6), 781-788.

Castel, C., Schweizer, M., Simonnot, M. O. \& Sardin, M. 2000 Selective removal of fluoride ions by a two-way ion-exchange cyclic process. Chem. Eng. Sci. 55(17), $3341-3352$.

Çengeloğlu, Y., Kır, E. \& Ersöz, M. 2002 Removal of fluoride from aqueous solution by using red mud. Sep. Purif. Technol. 28(1), $81-86$.

Dieye, A., Larchet, C., Auclair, B. \& Mar-Diop, C. 1998 Elimination des fluorures par la dialyse ionique croisée. Eur. Polym. J. 34(1), 67-75.

Ghorai, S. \& Pant, K. K. 2004 Investigations on the column performance of fluoride adsorption by activated alumina in a fixed-bed. Chem. Eng. J. 98(1-2), 165-173.

Gryta, M. \& Karakulski, K. 1999 The application of membrane distillation for the concentration of oil-water emulsions. Desalination 121(1), 23-29.

Hasson, D., Drak, A. \& Semiat, R. 200I Inception of $\mathrm{CaSO}_{4}$ scaling on RO membranes at various water recovery levels. Desalination 139(1-3), 73-81.

Hu, K. \& Dickson, J. M. 2006 Nanofiltration membrane performance on fluoride removal from water. J. Membr. Sci. 279(1-2), 528-529.

Mameri, N., Yeddou, A. R., Lounici, H., Belhocine, D., Grib, H. \& Bariou, B. 1998 Defluorination of septentrional Sahara water of North Africa by electro coagulation process using bipolar aluminum electrodes. Water Res. 32(5), $1604-1612$
Meenakshi \& Maheshwari, A. R. 2006 Fluoride in drinking water and its removal. J. Hazard. Mater. 137(1), 456-463.

Muthukumaran, K., Balasubramanian, N. \& Ramakrishna, T. V. I995 Removal of fluoride by chemically activated carbon. Indian J. Environ. Prot. 15, 514-517.

Qu, D., Wang, J. \& Hou, D. Y. 2009 Experimental study of arsenic removal by direct contact membrane distillation. J. Hazard. Mater. 163(2-3), 874-879.

Raichur, A. M. \& Basu, M. J. 20or Adsorption of fluoride onto mixed rare earth oxides. Sep. Purif. Technol. 24(1-2), 121-127.

Tahaikt, M., Achary, I., Menkouchi Sahli, M. A., Amor, A., Taky, M., Alami, A., Boughriba, A., Hafsi, M. \& Elmidaoui, A. 2004 Defluoridation of Moroccan ground water by electrodialysis: continuous operation. Desalination 167, 357.

Walha, K., Amar, R. B., Firdaous, L., Quéméneur, F. \& Jaouen, P. 2007 Brackish groundwater treatment by nanofiltration, reverse osmosis and electrodialysis in Tunisia: performance and cost comparison. Desalination 207(1-3), 95-106.

Wu, X. M., Zhang, Y. \& Dou, X. M. 2007 Fluoride removal performance of a novel $\mathrm{Fe}-\mathrm{Al}-\mathrm{Ce}$ trimetal oxide adsorbent. Chemosphere 69(11), 1758-1764.

Yang, C. L. \& Dluhy, R. 2002 Electrochemical generation of aluminum sorbent for fluoride adsorption. J. Hazard. Mater. 94(3), 239-252.

Younos, T. \& Tulou, K. E. 2005 Overview of desalination techniques. J. Contemp. Water Res. Educ. 132, 3-10.

Zakrzewska, T. G., Harasimowicz, M. \& Chmielewski, A. G. 200 I Membrane processes in nuclear technology-application for liquid radioactive waste treatment. Sep. Purif. Technol. 22-23(1), 617-625. 